\title{
Transmissão da Infeção HSV-1 da Criança para a Mãe Durante a Amamentação: Um Caso de Gengivostomatite Herpética
}

\section{Transmission of HSV-1 Infection from the Child to the Mother While Breastfeeding: A Case of Herpetic Gingivostomatitis}

Filipa Ribeiro Verdasca ${ }^{1}$

Autor Correspondente: Filipa Ribeiro Verdasca [filipa.r.verdasca@edu.nms.unl.pt] Avenida Ernest Solvay, N. ${ }^{\circ}$ 6, 3. ${ }^{\circ}$ C, 2625-166 Póvoa de Santa Iria, Portugal

\section{RESUMO}

A gengivostomatite herpética representa o quadro clínico mais frequente na primo-infeção pelo vírus herpes simplex 1, e afeta predominantemente crianças com idade entre 6 meses e 5 anos, e adultos jovens. A infeção transmite-se através de gotículas de saliva ou pelo contacto mucocutâneo direto com um indivíduo infetado.

O aleitamento materno, apesar de conferir proteção à criança, pode ser uma fonte de infeção. No entanto, são raros os casos na literatura em que é descrita a transmissão do vírus herpes simplex da criança para a mãe, durante a amamentação.

O presente caso refere-se a uma criança com 14 meses, internada por recusa alimentar, causada por gengivostomatite herpética. No quarto dia de internamento, a mãe tinha desenvolvido lesões herpéticas nos mamilos.

O objetivo é alertar para a transmissão deste vírus da criança infetada para a mãe, durante a amamentação.

PALAVRAS-CHAVE: Aleitamento Materno; Estomatite Herpética; Herpes Simples/transmissão; Herpesvírus Humano 1; Mamilos 


\section{ABSTRACT}

Herpetic gingivostomatitis represents the most common clinical picture in the herpes simplex virus 1 primary infection, affecting mainly children aged 6 months to 5 years, and young adults. The infection is transmitted through droplets of saliva or through direct mucocutaneous contact with an infected individual.

Breastfeeding, despite giving protection to the child, can be a source of infection. However, the cases in the literature describing transmission of the herpes simplex virus from child to mother during breastfeeding are rare.

This case refers to a 14-month-old child hospitalized for food refusal caused by herpetic gingivostomatitis. On the fourth day of hospitalization, the mother had developed herpetic lesions on the nipples.

The goal is to draw attention to the transmission of this virus from the infected child to the mother during breastfeeding.

KEYWORDS: Breast Feeding; Herpes Simplex/transmission; Herpesvirus 1, Human; Nipples; Stomatitis, Herpetic

\section{INTRODUÇÃO}

Os vírus herpes simplex (HSV-1 e HSV-2) produzem uma variedade de infeções, envolvendo superfícies mucocutâneas, o sistema nervoso central e órgãos viscerais.

O HSV-1 penetra em soluções de continuidade da pele ou das mucosas, permitindo a entrada do vírus nas células da epiderme e da derme, e começa a sua replicação no local da inoculação. ${ }^{1}$ De seguida, migra para os gânglios sensitivos e tecido nervoso contíguo, ficando em latência ao longo da vida. $\bigcirc$ gânglio trigeminal e os gânglios cervicais superior e inferior são afetados.

Assim que o vírus atinge a junção dermo-epidérmica, pode haver uma rápida contenção da infeção, propagação do vírus para a epiderme ou replicação do vírus e necrose das células epiteliais, e subsequente recidiva. ${ }^{2}$

As respostas dos hospedeiros influenciam a capacidade de resistência à infeção por HSV, a gravidade da mesma, o desenvolvimento e a manutenção do estado de latência, e a frequência das reativações. Estas podem ocorrer após estímulos desencadeantes, como imunossupressores ou processos infeciosos.

A infeção por HSV-1 é muito frequente, ocorrendo maioritariamente na infância e antes da infeção pelo HSV-2. Mais de 90\% dos adultos têm anticorpos contra HSV-1 aos 50 anos. ${ }^{2}$ A maioria das mães já está imune contra o HSV-1, transmitindo anticorpos aos filhos. Todavia, até aos 6 meses, estes perdem os anticorpos, ficando suscetíveis. Na idade adulta, ocorrem habitualmente as reativações.

Ambos os subtipos virais podem causar infeções genitais e orais-faciais e as infeções causadas pelos dois subtipos são clinicamente indistinguíveis. Contudo, aproximadamente 90\% dos casos de gengivostomatite herpética são causados pelo HSV-1, embora o HSV-2 também tenha sido identificado. ${ }^{3}$
As manifestações clínicas e o curso da infeção por HSV dependem do local anatómico envolvido, da idade, do estado imune do hospedeiro e do tipo antigénico do vírus. Em comparação com os episódios recorrentes, as infeções primárias são caracterizadas por uma maior duração dos sintomas e pelo isolamento do vírus a partir das lesões.

A gengivostomatite herpética representa a entidade clínica mais frequente resultante da infeção primária pelo HSV-1, enquanto que o herpes labial recorrente é mais comum na reativação do vírus. Apesar da maioria das infeções primárias por HSV serem assintomáticas, este quadro clínico ocorre em 25\% - 30\% das crianças infetadas. ${ }^{3}$ Porém, em adultos, a infeção primária por HSV assemelha-se à mononucleose.

O diagnóstico é baseado na presença de gengivas hiperemiadas, edemaciadas e friáveis, hemorragias gengivais e pequenas vesículas em erupção na mucosa jugal e a nível peri-oral. ${ }^{4}$ Os sintomas prodrómicos, tais como: febre, anorexia, irritabilidade, cefaleias e náuseas, podem ocorrer antes da apresentação do quadro clínico, após um período de incubação de 1 a 26 dias. $\bigcirc$ início da fase aguda pode ser acompanhado de sialorreia, halitose e adenopatias cervicais ${ }^{5}$ e pode durar 3 a 14 dias. As lesões orais podem ser dolorosas, levando a recusa alimentar com risco de desidratação. ${ }^{1}$

Epidemiologicamente, a gengivostomatite herpética ocorre em crianças com idade entre 6 meses e 5 anos e em adultos jovens. Raramente, pode ocorrer em recém-nascidos, em adultos e em idosos. Geralmente, é uma doença benigna e autolimitada a 7-10 dias.

As infeções por HSV ocorrem ao longo do ano. A transmissão do vírus dá-se através de gotículas de saliva ou pelo contacto mucocutâneo direto com indivíduos infetados. Nas fases de primo-infeção, o contágio é maior, pois as lesões estão muito ativas. Na amamentação, a disseminação deste vírus fica assim facilitada, pelo con- 
tacto direto e pela partilha de utensílios. A fase de contágio do HSV-1 dura cerca de 7 dias.

A causa mais comum de morbilidade na gengivostomatite herpética é a desidratação. Em casos graves, recomenda-se o internamento e a administração de líquidos parentéricos ${ }^{4}$ e, eventualmente, antivirais.

A meningoencefalite herpética é a complicação mais fatal da infeção por HSV. Em geral, a encefalite herpética é atribuída ao HSV-1, enquanto que a meningite é associada ao HSV-2.

Os critérios clínicos e laboratoriais são úteis para o diagnóstico de infeções por HSV. O diagnóstico clínico pode ser feito com precisão quando se apresentam múltiplas lesões vesiculares características. Contudo, estas podem assemelhar-se a lesões cutâneas de outras etiologias. Assim, estudos de laboratório são recomendados. A infeção por HSV é confirmada pela deteção de DNA viral em raspagens de lesões. A deteção de DNA do HSV por polymerase chain reaction (PCR) é a técnica mais sensível. A confirmação laboratorial permite a subtipagem do vírus, que pode ajudar a prever a frequência de reativação após o primeiro episódio de infeção por HSV.

O aciclovir é o agente mais utilizado para o tratamento de infeções por HSV. O valaciclovir e o fanciclovir mostraram-se também eficazes na diminuição da duração dos sintomas e lesões de infeções mucocutâneas de HSV. Num primeiro episódio, a dose recomendada de aciclovir oral é $15 \mathrm{mg} / \mathrm{kg} /$ dose, cinco vezes por dia, ou 20 mg/kg/dose de 6-6 horas, ${ }^{1}$ durante 5 a 10 dias. A terapêutica com aciclovir está aconselhada nas primeiras 72 horas de doença. ${ }^{1}$

A alimentação oral deve ser líquida ou mole e fria, de forma a diminuir o desconforto e a dor na mucosa oral. Pode ser necessário recorrer à hidratação por sonda naso-gástrica ou via endovenosa, nos casos de recusa alimentar total. Os analgésicos e antipiréticos também são usados.

O aleitamento materno, pelas diversas vantagens que confere à mãe e à criança, é reconhecido como a melhor forma de alimentação. Porém, doenças que envolvem quer a mãe, quer a criança, podem constituir obstáculos à amamentação.

A mãe que amamenta, ao apresentar sintomas de uma doença, provavelmente já terá transmitido a infeção ao filho, e a orientação geral é manter o aleitamento. ${ }^{6}$ Se suspender a amamentação, a proteção do lactente fica diminuída, aumentando a probabilidade de este adoecer, porque deixará de receber anticorpos específicos e outros fatores de proteção. No entanto, o leite mater- no também pode ser fonte de infeção para a criança, em certas doenças maternas. Não obstante, o risco de transmissão do vírus herpes simplex pelo leite materno é muito baixo.

Raros são os casos descritos da transmissão da infeção por HSV da criança para a mãe durante a amamentação, não existindo recomendações formuladas relativamente ao aleitamento materno na infeção por HSV-1 da criança. De facto, apenas é uma contraindicação à amamentação, segundo as normas publicadas, a presença de vesículas herpéticas localizadas na mama, nomeadamente nos mamilos. 6 Se a criança estiver infetada por herpes simples, deve ser isolada de outras crianças, mas não da mãe.

\section{CASO CLÍNICO}

Criança de 14 meses, do sexo feminino, sem antecedentes pessoais e familiares de relevo, que não iniciou a diversificação alimentar, recorreu ao Serviço de Atendimento Permanente Pediátrico no Hospital CUF Almada, por febre elevada $\left(39,5^{\circ} \mathrm{C}\right)$ e recusa alimentar com 4 dias de evolução. Ao exame objetivo, apresentava gengivas hiperemiadas e friáveis, lesões vesiculares periorais e lesões ulceradas na língua e mucosa oral. Estava prostrada, eupneica, sem tiragem, tinha a língua pastosa, mas com turgor cutâneo mantido e sialorreia.

O restante exame objetivo estava normal. Negava vómitos, diarreia e outros sintomas.

Foi diagnosticada com gengivostomatite herpética e, por intolerância da via oral e recusa alimentar completa, ficou internada no Hospital CUF Descobertas.

Iniciou hidratação endovenosa, aciclovir EV e solução oral de estomatites.

A febre cedeu aos antipiréticos que iniciou (paracetamol e ibuprofeno).

Dos exames complementares de diagnóstico, salientam-se análises sanguíneas com parâmetros inflamatórios baixos, sem leucocitose ou neutrofilia, e anemia microcítica normocrómica (Hb: 9,6 g/dL, VGM: 66 fL, CHGM: 32 g/dL, leucócitos 7600*10/uL, neutrófilos 56\%, PCR: $5,7)$. Este tipo de anemia é, na maioria dos casos, associado a ferropenia. Nesta criança, possivelmente pelo facto da ingestão inadequada de ferro alimentar ser agravada por doença aguda, que resultou em recusa alimentar, numa fase do desenvolvimento em que há uma rápida velocidade de crescimento.

A partir dos 6 meses, o volume ingerido pelo lactente amamentado torna-se insuficiente para suprir as ne- 
cessidades em ferro, pelo que a criança foi referenciada para um Pediatra Assistente, para orientação e estudo do ferro e início de suplementação.

A partir do terceiro dia de internamento, começou a melhorar progressivamente, ficando apirética no quarto dia. Verificou-se regressão das lesões orais e melhoria do estado de hidratação. Após cumprir 5 dias de terapêutica com aciclovir endovenoso, teve alta com boa tolerância oral.

Estava sob aleitamento materno, sendo que, durante o internamento, a mãe da criança tinha desenvolvido múltiplas vesículas de base eritematosa nos mamilos. No quarto dia de internamento, a mãe apresentava odinofagia e lesões vesiculares na porção posterior da faringe, tendo sido diagnosticada com faringoamigdalite herpética (que surge na primo-infeção por HSV-1 em adultos) e medicada com aciclovir oral.

\section{DISCUSSÃO}

A transmissão de herpes à mãe durante a amamentação é um tema pouco descrito na literatura, sendo pertinente para a prática clínica o presente caso. As infeções primárias por herpes simplex são comuns em crianças, no entanto, provavelmente a forma de transmissão mencionada é rara: pelo facto de a maioria das crianças infetadas já não ser amamentada; ou por não se ter esclarecido a fonte da infeção: a mãe ou a criança. ${ }^{7}$

Neste caso, possivelmente o trauma causado pela sucção durante a amamentação originou lesões de continuidade nos mamilos da mãe, que facilitaram o desenvolvimento de vesículas herpéticas nos mesmos. Posteriormente, a mãe apresentava um quadro clínico de faringoamigdalite herpética, confirmando, assim, a transmissão do HSV-1 pelo lactente.

As análises serológicas demonstram que a maioria dos adultos já foi infetada com HSV.? Todavia, apesar da transmissão do HSV-1 à mãe durante a amamentação ser rara, é apropriado advertir as mães de crianças com gengivostomatite herpética da possibilidade de serem infetadas e das complicações que possam surgir. ${ }^{8}$ Desta forma, a mãe poderá ponderar outras formas de alimentação da criança.

Torna-se essencial compreender os fatores que influenciam esta forma rara de transmissão do HSV, de modo a adotar medidas preventivas, dados os múltiplos benefícios da amamentação e poucas contraindicações associadas. A infeção pelo vírus herpes simplex é uma delas, mas só se há lesões no mamilo da mãe.
Como a transmissão de HSV da criança para a mama é rara, esta não é uma contraindicação à amamentação. Se a transmissão ocorrer, como neste caso, a mãe pode ser tratada e o aleitamento materno está contraindicado segundo as guidelines. No entanto, nas gestações subsequentes, é possível que uma mãe infetada desta forma transmita a infeção por HSV ao próximo filho durante a amamentação, e ela deve ser alertada para esse risco.

Uma vez que o diagnóstico imediato e o tratamento da infeção pelo HSV são importantes nos recém-nascidos, e dado que pode resultar numa infeção disseminada, os médicos devem estar atentos ao examinar lesões vesiculares nos mamilos da mãe durante o período neonatal.

CONFLITOS DE INTERESSE: Os autores declaram não ter qualquer conflito de interesse na realização do presente trabalho.

FONTES DE FINANCIAMENTO: Não houve qualquer fonte de financiamento na realização do presente trabalho.

CONFIDENCIALIDADE DOS DADOS: Os autores declaram ter seguido os protocolos da sua instituição acerca da publicação dos dados de doentes.

PROTEÇÃO DE PESSOAS E ANIMAIS: Os autores declaram que os procedimentos seguidos na elaboração do presente trabalho estão em conformidade com as normas das comissões de investigação clínica e de ética, bem como da declaração de Helsínquia e da Associação Médica Mundial.

CONFLICTS OF INTEREST: The authors declare that they have no conflicts of interest.

FINANCIAL SUPPORT: This work has not received any contribution, grant or scholarship.

CONFIDENTIALITY OF DATA: The authors declare that they have followed the protocols of their work center on the publication of data from patients.

PROTECTION OF HUMAN AND ANIMAL SUBJECTS: The authors declare that the procedures followed were in accordance with the regulations of the relevant clinical research ethics committee and with those of the Code of Ethics of the World Medical Association (Declaration of Helsinki).

\section{REFERÊNCIAS}

1. Roda J, Salgado M. Gengivoestomatite herpética ou febre aftosa na criança? Saúde Inf. 2010;32:135-136.

2. Longo DL, Fauci AS, Kasper DL, Hauser SL, Jameson J, Loscalzo J. Harrison's Principles of Internal Medicine. $19^{\text {th }}$ ed. New York: McGraw-Hill; 2015. 
3. Kolokotronis A, Doumas S. Herpes simplex virus infection, with particular reference to the progression and complications of primary herpetic gingivostomatitis. Clin Microbiol Infect. 2006;12:202-11.

4. Goldman, R. Acyclovir for herpetic gingivostomatitis in children. Can Fam Physician. 2016;62:403-4.

5. Kliegman R, Marcdante K. Nelson Essentials of Pediatrics. $7^{\text {th }}$ ed. Amsterdam: Saunders; 2015.

6. Lamounier J, Moulin Z, Xavier C. Recomendações quanto à amamentação na vigência de infecção materna. J Pediatr. 2004;80:181-8.

7. Sealander JY, Kerr CP. Herpes simplex of the nipple: infant to mother transmission. Am Fam Physician.1989;39:111-3.

8. Gupta S, Malhotra A, Dash S. Child to mother transmission of herpes simplex virus-1 infection at an unusual site. J Eur Acad Dermatol Venereol. 2008;22:878-9. 